\title{
Tratados Destinados a Evitar a Bitributação Internacional Sobre a Renda e a sua Relação com os Investimentos que Envolvem o Brasil
}

\begin{abstract}
Resumo
Visando combater a evasão fiscal e facilitar o fluxo de investimentos, os países celebram acordos destinados a combater a bitributação da renda. O estudo tem como objetivo investigar o impacto dos tratados para evitar a dupla tributação da renda nas relações de investimentos estrangeiros diretos do Brasil. A análise compreendeu 162 países e jurisdições com os quais ocorreram transações de investimentos provindos do Brasil ou que o tenham como receptor, no período de 2005 a 2011. Aplicou-se a técnica de análise de dados em painel, pela seleção de seis variáveis independentes, a fim de verificar o comportamento dos tratados de dupla tributação diante dos investimentos. Verificou-se, por meio do modelo estimado, que esses tratados tiveram impacto positivo e estatisticamente significante - se comparado com estudos anteriores - no volume de investimento estrangeiro direto. Dividindo-se a amostra entre os investimentos recebidos e realizados pelo Brasil, identificouse que o aumento foi maior no investimento estrangeiro direto recebido $(130,1 \%)$ do que no realizado $(76,9 \%)$, ainda que, em ambas as análises, esta tenha sido a segunda variável de maior impacto positivo no modelo. Conclui-se que, exclusivamente no cenário brasileiro, a dupla tributação internacional da renda é fator relevante na decisão de investimento, uma vez que a presença de tratados que buscam assegurar o investidor no recebimento de rendimento sem dupla tributação incrementa, substancialmente, os fluxos de investimento. O presente estudo diferencia-se dos anteriores pela amostra que contém apenas tratados em vigor no Brasil.
\end{abstract}

Palavras-chave: Bitributação internacional; Investimento estrangeiro direto; Tributação sobre a renda.

\section{Jonatas de Pessoa \\ Albuquerque Martins \\ Bacharel em Ciências Contábeis pela Universidade Federal do Ceará e Assistente em Administração do Departamento de Contratos e Execução Orçamentária da Universidade Federal do Ceará. Contato: Rua Desembargador João Firmino, 340 apt. 201 - Bl. G. Montese. CEP.: 60425-560. Fortaleza-CE. E-mail: jonatas.martins@ymail.com}

\section{Jackeline Lucas Souza}

Mestre em Administração de Empresas pela Universidade de Fortaleza - Unifor e Professora da Universidade Federal do Ceará (UFC). Contato: Rua Torres Câmara, 891, ap. 702. Aldeota. CEP.: 60150-060. Fortaleza-CE.

E-mail: jackeline.souza@hotmail.com 


\section{Introdução}

Segundo Silva (2008), a dupla tributação internacional ocorre quando há um concurso de normas tributárias emanadas por mais de uma soberania tributária, submetendo o mesmo contribuinte, pelo mesmo fato gerador, a um imposto da mesma espécie em um mesmo período de tempo. A dupla tributação internacional da renda não é desejada pelos países, uma vez que a globalização e a abertura dos mercados aos investimentos internacionais têm elevado o fluxo de capitais.

Partindo da premissa de que quanto maior a carga tributária menor a ocorrência investimentos estrangeiros, os países podem assinar acordos a fim de permanecerem atraentes ao capital externo.

De acordo com Bellan (2010), o Brasil, ao longo das últimas décadas, assinou e ratificou diversos tratados para evitar a dupla tributação, bem como ampliou suas transações comerciais, com consequente aumento no volume de investimentos estrangeiros direto, recebidos e realizados. Com a finalidade de analisar esse aumento de investimentos, o presente estudo busca investigar o impacto dos tratados destinados a evitar a bitributação internacional sobre a renda nas relações de investimentos do Brasil, sobre a formulação do seguinte questionamento: Qual o impacto causado pelos tratados destinados a evitar a bitributação internacional sobre a renda com os investimentos recebidos e realizados pelo Brasil?

Para alcance do objetivo geral proposto, foram traçados os seguintes objetivos específicos: i) caracterizar a bitributação sobre a renda e seus efeitos sobre os investimentos; ii) analisar, em estudos anteriores, as variáveis empregadas pelos autores como determinantes de investimento em seus modelos estatísticos; e, iii) identificar os investimentos estrangeiros direto, em estoque, e sua relação com os tratados.

$\mathrm{Na}$ metodologia utilizada, foram selecionadas oito variáveis que haviam sido empregadas por estudos empíricos anteriores, como parâmetros de comparação com os tratados para evitar a dupla tributação em relação aos seus impactos nos investimentos, constatados a partir da aplicação da técnica de análise de dados em painel, em investimentos estrangeiros diretos realizados e recebidos pelo Brasil, no período de 2005 a 2011, em 162 países e jurisdições.

O presente trabalho está estruturado em cinco seções, sendo esta primeira a introdução; a segunda, uma abordagem teórica, analisando os tratados segundo o ordenamento jurídico brasileiro, com foco em matéria tributária e em estudos feitos sobre a dupla tributação internacional; a terceira descreve a metodologia empregada, com o detalhamento dos períodos analisados, fontes dos dados, amostra e procedimentos estatísticos; a quarta apresenta a análise dos resultados apresentados; e, por fim, a quinta e última seção, as considerações finais.

\section{Fundamentação Teórica}

Tratado é todo acordo formal, fruto da manifestação de dois ou mais sujeitos do Direito Internacional Público, a fim de produzir efeitos jurídicos para as partes contratantes, de acordo com as normas internacionais (Mazzuoli, 2011).

Para Mazzuoli (2011), se o acordo se enquadrar na definição prevista no Art. 2º inc. I, alínea "a" da Convenção de Viena sobre o Direito dos Tratados de 1969 - a qual o Brasil é signatário -, não importa o nome a que lhe atribuam. Tal Convenção define Tratado como um acordo internacional escrito entre Estados e regido pelo Direito Internacional, quer conste de um instrumento único, quer de dois ou mais instrumentos conexos, qualquer que seja sua denominação específica.

No Brasil, apenas o Presidente da República pode assinar tratados, convenções e atos internacionais, sujeitos a referendo do Congresso Nacional (inciso VIII do Art. 84 da Constituição Federal-CF, de 1988). A CF/88, em seu inciso I do Art. 49, atribui competência exclusiva ao Congresso para a resolução de questões sobre tratados, acordos ou atos internacionais, por meio da elaboração de decreto-legislativo.

Os tratados, conforme Mazzuoli (2011), podem ser bilaterais quando possuem apenas duas partes contratantes, ou multilaterais, quando celebrados por mais de duas partes. Quanto à sua natureza jurídica, para 
Silva (2007), são classificados em tratados-lei quando as partes contratantes convergem para a criação de normas de Direito Internacional Público, ou tratados-contrato quando a vontade das partes é divergente e resulta de concessões mútuas, a fim do cumprimento das suas respectivas obrigações, visando a um objetivo em comum.

Contextualizando a definição de tratado no âmbito tributário, para Silva (2007), é um acordo jurídico, de natureza negocial, celebrado entre dois ou mais países, visando, principalmente, solucionar possíveis conflitos sobre a dupla tributação da renda que podem ocorrer no cenário internacional.

Acerca da matéria, o Art. 98 do CTN (1966) dispõe que "os tratados e as convenções internacionais revogam ou modificam a legislação tributária interna, e serão observados pela que lhes sobrevenha". Mazzuoli (2011, p. 386) enfatiza que tal dispositivo atribui primazia aos tratados internacionais em matéria tributária sobre toda a legislação tributária interna. Portanto, nenhuma legislação que seja contrária ao disposto no tratado anteriormente firmado e em vigor no Brasil poderá ser aplicada sem que antes seja feita a denúncia do tratado, caso este não mais satisfaça aos interesses nacionais.

Na prática, o Supremo Tribunal Federal (STF) tem considerado que o Art. 98 do CTN é aplicável apenas aos tratados-contrato e, não, aos tratados-lei. Segundo Xavier (2007), essa jurisprudência parte da premissa de que a Constituição é omissa quanto à supremacia hierárquica dos tratados e que o Art. 98 do CTN estaria invadindo, de forma ilegítima, uma competência constitucional exclusiva.

Ademais, é oportuno citar que a Receita Federal do Brasil (RFB) é competente para interpretar e aplicar os tratados de bitributação, juntamente com o Conselho Administrativo de Recursos Fiscais, tendo em vista que, ao ratificar um tratado em matéria tributária, é dever do Estado zelar pelo seu cumprimento, adequando o seu sistema tributário para este fim (Gonzaga, 2010).

\subsection{A Dupla Tributação Internacional}

A dupla tributação envolve a relação do contribuinte com o fisco de dois ou mais Estados. Segundo Xavier (2007), é resultado do concurso de normas dentro do plano do Direito Tributário, quando o mesmo fato se integra na hipótese de incidência de duas normas tributárias distintas, originando a constituição de mais do que uma obrigação de imposto. Vale ressaltar que, neste caso, há uma justaposição ou sobreposição de normas, mas não um conflito entre elas.

Isso ocorre porque os países detêm soberania, um atributo fundamental que acompanha o Estado, e do qual ele não pode abrir mão, pois faz parte da sua essência. Explica Silva (2007) que, por meio dessa soberania, o Estado dispõe do poder de institucionalizar um sistema tributário e de tributar e, uma vez que apenas os Estados possuem soberania tributária, a celebração de tratados em matéria tributária, compete, pois, somente a eles. Os Estados devem, então, limitar parte da sua soberania tributária e chegar a um denominador comum por razões econômicas e fiscais. Para tanto, Faria (2006) explica que o fenômeno da dupla tributação internacional ocorre quando mais de uma soberania tributária submete o mesmo contribuinte, pelo mesmo fato gerador, a um imposto da mesma espécie em um mesmo período tributário.

Os Estados adotam uma das seguintes estruturas de tributação, de acordo com Silva (2007): a) territorialidade, ou critério da fonte - somente os rendimentos e proventos obtidos dentro dos limites fronteiriços nacionais são tributados; e, b) universalidade, ou critério da residência ou nacionalidade - tributa os rendimentos e proventos do contribuinte, independentemente do local em que eles foram obtidos, observando-se apenas a residência ou o seu domicílio.

Dentro dessas estruturas de tributação, as hipóteses de incidência, segundo Moreira (2003), são que: a) dois ou mais Estados que adotem o princípio da territorialidade considerem que determinado rendimento foi auferido dentro de seus respectivos territórios; b) um Estado adota o princípio da universalidade, com pretensões extraterritoriais, e outro adota o princípio da territorialidade; e, c) ambos os Estados adotam o princípio da universalidade e consideram que determinado contribuinte é nacional ou residente de ambos os Estados. 
O Brasil passou a adotar, após o advento da Lei no 9.249, de 26 de dezembro de 1995, o critério da universalidade ao invés do critério da territorialidade para tributar a renda das pessoas jurídicas. $\mathrm{O}$ caput do Art. 25 da referida lei dispõe que "os lucros, rendimentos e ganhos de capitais auferidos no exterior serão computados na determinação do lucro real das pessoas jurídicas correspondente ao balanço levantado em 31 de dezembro de cada ano". Para Faria (2006), os países celebram tratados a fim de evitar a bitributação nos movimentos de capitais e de pessoas, nas transferências de tecnologia, no intercâmbio de bens, serviços e propriedade intelectual, na difusão cultural e no direito autoral.

Uma proposta de tributação mundial, segundo Avi-Yonah (2007), é o princípio de tributação única, onde a renda proveniente de transações no exterior deveria ser passível de tributação uma só vez, pois a dupla tributação pode asfixiar investimentos internacionais. Por outro lado, a ausência de tributação nessas transações ofereceria uma oportunidade de fuga à tributação doméstica ao se investir no exterior, prejudicando a arrecadação nacional.

Para contornar esse problema e evitar que o contribuinte seja duplamente tributado, os Estados utilizam diversos métodos, por medidas unilaterais, bilaterais ou multilaterais, em que os tratados, para evitar a dupla tributação (TDTs), classificam-se como uma medida bilateral.

Diversos modelos de TDTs são desenvolvidos, sendo o mais utilizado pelos países o modelo da Organização para a Cooperação e Desenvolvimento Econômico (OCDE). Este modelo divide os rendimentos em categorias específicas, tratando tanto a tributação da renda das pessoas jurídicas quanto das pessoas físicas.

Segundo o Departamento de Corte de Receitas e Aduna (Her Majesty's Revenue and Customs) existem mais de 2.500 acordos que se referem à eliminação da bitributação no mundo. No Brasil, de acordo com os dados obtidos no sítio da RFB (2013), 28 tratados bilaterais estão em vigor, seguindo os padrões da OCDE, a fim de permitir maior fluxo de investimentos estrangeiros diretos (IED).

\subsection{Os Investimentos Estrangeiros Diretos e sua relação com os Tratados para Evitar a Dupla Tributação}

Os investimentos estrangeiros podem ser realizados na forma de investimentos diretos ou em carteira. O que diferencia as modalidades é que, no investimento direto, o investidor detém $10 \%$ ou mais das ações ordinárias ou do direito a voto em uma empresa, enquanto que, no investimento em carteira, esse percentual é inferior a 10\%. De acordo com a RFB (2014), o investimento direto dividese em duas modalidades: participação no capital (ingressos de recursos de bens, moeda e as conversões externas em investimento estrangeiro direto, incluindo os valores destinados ao programa de privatizações, relacionados com a aquisição, subscrição e o aumento total ou parcial do capital social de empresas residentes) e empréstimos intercompanhias (créditos concedidos pelas matrizes, sediadas no exterior, a suas subsidiárias ou filiais estabelecidas no país).

Para Alvim e Moraes (2013), as políticas implementadas na década de 90 com foco na abertura comercial e desregulamentação, estabilização macroeconômica e privatização mudaram o perfil da economia brasileira, até então isolada do comércio internacional pelo protecionismo, e viabilizaram uma maior atração de IED pelo Brasil. De acordo com Paixão (2014), essa mudança permitiu que o país acompanhasse o movimento ocorrido nos anos 2000, em que os países desenvolvidos foram perdendo participação de forma progressiva para os emergentes, passando estes a concentrarem mais da metade dos influxos de IED a partir de 2010, tendo o Brasil posição de destaque não apenas regional, mas mundial.

De modo geral, dados divulgados pelo Instituto de Pesquisa Econômica Aplicada (IPEA, 2010), apontam que, a partir da abertura econômica, a taxa de expansão dos fluxos de IED realizado pelo país tem superado a expansão de investimentos provenientes de outros países no Brasil, ainda que este se mantenha como um dos principais polos de atração para esse tipo de investimento. A relação entre IED realizado e recebido cresceu de $8,7 \%$, no período $1990-2000$, para 51,7\%, no período 2004-2008. As altas taxas, entretanto, explicam-se pelo pequeno volume inicial, haja vista que o país estava ainda ingressando nessa modalidade de negócio internacional. 
Tendo em vista que o rendimento auferido pela realização de investimentos no exterior é passível de tributação sobre a renda, a existência de tratados internacionais contra a dupla tributação poderia reduzir os custos de investir e, consequentemente, estimular o fluxo de investimentos internacionais. Nesse sentido, Gonzaga (2010) explica que, nos países os quais a carga tributária elevada representa um custo alto para a contabilidade das empresas, a presença de tais tratados pode ser um fator determinante para os investidores.

Faria (2006) complementa que os tratados internacionais, em matéria tributária, objetivam incrementar o fluxo de investimentos para o Brasil e permitem a adoção de instrumentos de incentivos fiscais, criando um clima de segurança para o investidor estrangeiro e possibilitando a redução do imposto incidente sobre o lucro auferido por empresas brasileiras no exterior e sobre os rendimentos transferidos ao país por filiais de empresas brasileiras.

Há, porém, outra hipótese, na qual os TDTs objetivam apenas o combate à evasão fiscal, partindo de sua cláusula de troca de informações, ao invés de procurar aumentar o fluxo de investimentos. Esse tipo de tratado poderia inclusive ter um impacto negativo para os investidores, ao exigir uma maior transparência por parte deles, como apontado nos estudos de Bloningen e Davies (2004) e Egger, Larch, Pfaffermayr e Winner (2006).

\subsection{Estudos empíricos anteriores}

Alguns autores começaram a procurar verificar a relação, ou a falta dela, entre TDT e IED. Os estudos ainda não conseguiram chegar ao consenso a respeito do tema, pois os resultados têm divergido bastante devido a variações de amostra e de métodos de análise de cada um deles.

Davies (2003) examinou o impacto de 20 renegociações de TDTs entre os anos de 1966 e 2000 nos IEDs dos Estados Unidos e concluiu que essas renegociações não impactaram no fluxo de investimentos tanto interno quanto externo.

Bloningen e Davies (2004) também evidenciaram nas relações de IED recebido e realizado dos Estados Unidos, com 88 países parceiros no período de 1980 a 1999. A análise diferenciou os tratados antigos, concluídos antes do início do período amostra, e os novos tratados, concluídos a partir de 1980, encontrando TDTs que não tiveram efeito positivo em ambas as situações.

Bloningen e Davies (2005) utilizaram dados da OCDE sobre estoques e fluxos de IED, cobrindo 23 países desenvolvidos entre 1982 e 1992, encontrando relação positiva entre os tratados e os grandes fluxos e os estoques de IED. Dividindo-se a amostra entre novos e antigos tratados, o impacto destes permaneceu positivo, enquanto que os novos apresentaram uma influência negativa, mas não estatisticamente significante.

Egger et al. (2006) estimaram o efeito dos tratados de tributação no IED bilateral em um universo amostral de 67 pares de países da OCDE com tratados e 719 pares sem tratados, no período 1985-2000. Concluíram que os tratados tiveram um efeito negativo no IED.

Neumayer (2007) se baseou em 114 TDTs dos Estados Unidos e dados agregados de 120 países em desenvolvimento receptores de IED, evidenciando que os TDTs estimularam os IEDs em $22 \%$. Ao dividir a amostra entre países cuja renda da população é considerada mediana e países de baixa renda per capita, percebeu que o aumento ocorreu apenas no primeiro grupo, não havendo os TDTs produzido efeito positivo no segundo.

Wu (2008) não encontrou forte evidência de que os TDTs aumentam as atividades de IED quando analisou os 16 TDTs e o histórico de investimentos do país, em Taiwan.

Barthel, Busse, Krever e Neumayer (2010) selecionaram dados da UNCTAD (Conferência das Nações Unidas sobre Comércio e Desenvolvimento) e da OCDE sobre a saída de IED em 30 países, sendo 10 em desenvolvimento, e da entrada de IED em 105 países, sendo 84 em desenvolvimento. Ambas as análises foram realizadas com dados do período de 1978 a 2004, descobrindo uma relação positiva entre a existência de TDT e o aumento de IED bilateral. 
O presente estudo diferencia-se dos anteriores à medida que utiliza uma amostra que contém apenas TDT em vigor no Brasil e procura identificar a relação entre essas duas variáveis no plano nacional, enquanto que os anteriores abordaram o assunto utilizando como base os países membros da OCDE, de acordo com Barthel, Busse, Krever et al. (2010), Neumayer (2007), Egger et al. (2006), Bloningen e Davies (2005), Bloningen e Davies (2004) e Davies (2003).

\section{Metodologia}

No intuito de encontrar uma solução para o problema proposto, realizou-se uma pesquisa descritiva, com o objetivo de avaliar e descrever as características de questões pertinentes a um determinado problema (Collis \& Hussey, 2005). Além disso, a pesquisa é exploratória, pois tem a finalidade de promover maior familiaridade com o tema, bem como sua utilidade quando não se tem uma noção abrangente sobre o assunto a ser estudado (Roesch,2006).

Dentro desse contexto, buscou-se investigar o impacto dos tratados para evitar a dupla tributação da renda sobre os investimentos estrangeiros diretos, utilizando uma abordagem quantitativa nos dados secundários por métodos estatísticos na análise e interpretação destes dados (Corbin \& Strauss, 2008). Em complemento, uma pesquisa documental e bibliográfica foi realizada, sendo a bibliográfica pela análise do que já foi publicado sobre o tema, sobretudo em livros e artigos científicos; e a documental, pela utilização de documentos escritos de fontes primárias, como leis, tratados e decretos, e de fontes secundárias, como relatórios e tabelas estatísticas.

No período de 2005 a 2011, foi identificado, por conta da irregularidade na divulgação de dados sobre IED recebido e realizado em períodos concomitantes, que só seria possível a análise ser realizada nos anos de 2005 e 2011. A base de dados utilizada para os investimentos estrangeiros direto no Brasil contém informações sobre 145 países que realizaram investimentos no Brasil no período, enquanto que nos investimentos realizados pelo Brasil no exterior têm-se informações sobre 133 países. Ambos os dados foram coletados nos sítios do Banco Central do Brasil e do Fundo Monetário Internacional, em milhões de dólares e em preços constantes.

Foi aplicada a técnica de análise de dados em painel devido à natureza longitudinal da nossa base de dados, primeiramente para os dados de estoque de IED realizado $\left(\operatorname{IED}_{S}\right)$ e em seguida de estoque de IED recebido $\left(\mathrm{IED}_{\mathrm{E}}\right)$. Os estoques de investimentos, por terem volume de transações bem diferenciadas nos países, foram utilizados em logaritmos, a fim de obter maior uniformidade na análise dos dados. O software utilizado foi o R (2014), mais especificamente o pacote "plm", desenvolvido por Croissant e Millo (2008).

As variáveis independentes selecionadas são determinantes de investimentos empregados nos estudos empíricos anteriores de Barthel, Busse e Neumayer (2010), Neumayer (2007), Bloningen e Davies (2005; 2004) e Davies (2003), que representam fatores que podem impactar na decisão para o fluxo de investimento (Figura 1 e Equação 1). Assim, o nosso modelo terá a seguinte forma:

$$
Y_{i t}=\alpha+\beta 1 T D T_{i t}+\beta 2 A C_{i t}+\beta 3 P I B P C_{i t}+\beta 4 D I S T_{i t}+\beta 5 S P I B_{i t}+\beta 6 Q D I F P I B_{i t}+\varepsilon_{i t}
$$


Onde:

i País

t Tempo

Y variável dependente (estoque de IED), em dólares;

a interceptação da reta com o eixo vertical;

$\beta_{1}$ a $\beta_{6}$ parâmetros das variáveis independentes, efeito de $X$ sobre $Y$;

TDT presença ou não de tratado de dupla tributação entre os países;

AC presença ou falta de acordo regional de comércio entre os países;

$\mathrm{PIB}_{\mathrm{PC}}$ produto interno bruto per capita do país receptor do investimento, em dólares;

DIST distância entre as capitais dos países, em km;

SPIB logaritmo da soma do PIB dos países, em dólares;

QDIFPIB logaritmo do quadrado da diferença entre o PIB dos países, em dólares, e;

$\varepsilon$ termo de erro ou perturbação, contendo fatores não observados que afetam $Y$.

Segundo Greene (2012), a principal vantagem do uso de dados em painel ao invés de dados cross section é que o primeiro permite grande flexibilidade ao pesquisador para modelar as diferenças de comportamento entre os indivíduos, também chamada de heterogeneidade entre os indivíduos. Quando esta heterogeneidade é observada, Greene (2012) afirma que a estimação de mínimos quadrados ordinários com dados empilhados (pooling) fornece estimativas eficientes aos parâmetros do modelo. Já quando esta heterogeneidade não é observada e correlacionada com as variáveis independentes do modelo, deve-se utilizar o modelo de efeitos fixos. E, finalmente, quando não há correlação entre as variáveis independentes e a heterogeneidade não observada, deve-se utilizar o modelo de efeitos aleatórios. Para decidir qual modelo melhor se ajusta aos nossos dados, utilizaram-se os testes F, a fim de testar a presença de efeitos fixos; o teste dos multiplicadores de Lagrange de Breusch e Pagan, para testar a presença de efeitos aleatórios; e o teste de Hausman, para testar entre os efeitos aleatórios e os efeitos fixos (maiores detalhes acerca dos métodos com dados em painel, ver Greene (2012) e Wooldridge (2010).

Buscou-se identificar, dentre as variáveis que haviam sido empregadas em estudos empíricos anteriores, as que melhor se adequavam à realidade brasileira, a fim de que a análise não seja afetada por dados de pouca ou nenhuma relevância.

\begin{tabular}{|c|c|c|c|}
\hline Var. Indep. & Sigla & Objetivo da Variável & Fonte dos dados \\
\hline $\mathrm{X}_{1}$ & TDT & $\begin{array}{l}\text { Variável dummy, que verifica o impacto dos tratados para evitar a } \\
\text { dupla tributação da renda sobre os estoques de investimento direto. } \\
\text { É a variável independente mais relevante para o presente estudo. } \\
\text { Indica se há TDT em vigor entre os países, considerando o ano da } \\
\text { sua entrada em vigor no Brasil. }\end{array}$ & $\begin{array}{l}\text { Receita Federal } \\
\text { do Brasil }\end{array}$ \\
\hline $\mathrm{X}_{2}$ & $A C$ & $\begin{array}{l}\text { Variável dummy, assinalando a assinatura de acordo regional } \\
\text { de comércio entre os países. Tais acordos podem ser uniões } \\
\text { aduaneiras ou acordos de livre comércio. }\end{array}$ & $\begin{array}{l}\text { Organização Mundial } \\
\text { do Comércio }\end{array}$ \\
\hline$x_{3}$ & $\mathrm{PIB}_{\mathrm{PC}}$ & $\begin{array}{l}\text { O PIB per capita é um fator que pode influenciar o poder de compra } \\
\text { dos consumidores domésticos. }\end{array}$ & Banco Mundial \\
\hline$X_{4}$ & DIST & $\begin{array}{l}\text { Verifica como a distância entre os países influencia a atração de } \\
\text { investimentos. }\end{array}$ & Distancefromto.net \\
\hline$x_{5}$ & SPIB & $\begin{array}{l}\text { A soma do PIB dos países analisa se economias maiores e mais } \\
\text { similares tendem a lidar melhor com as variações de mercado que } \\
\text { impactam nos investimentos. }\end{array}$ & Banco Mundial \\
\hline$X_{6}$ & QDIFPIB & $\begin{array}{l}\text { Países com grandes diferenças econômicas teriam dificuldades em } \\
\text { manter relações de investimentos entre si. }\end{array}$ & Banco Mundial \\
\hline
\end{tabular}

Figura 1. Nomenclatura das variáveis independentes

Fonte: elaborado pelos autores (2014) 
Os dados foram coletados entre os meses de setembro de 2012 e janeiro de 2013. A amostra foi dividida em duas partes, entre IED realizado e recebido, compondo a primeira parte por 133 países e jurisdições com os quais o Brasil realizou investimentos diretos; e a segunda parte, com 145 países e jurisdições de investimentos recebidos no Brasil.

\section{Análise de Resultados}

Primeiramente, foi analisado o modelo, considerando o IED realizado pelo Brasil. A Tabela 1 a seguir mostra as estatísticas descritivas das variáveis utilizadas. Nota-se que 20,8\% dos países que receberam investimentos brasileiros no período de 2005 a 2011 têm acordo para evitar a dupla tributação com o Brasil.

Tabela 1

Estatísticas descritivas dos dados - IED realizado

\begin{tabular}{cccrrrr}
\hline Variável & Média & Desvio-Padrão & Mínimo & Máximo & $\mathbf{N}$ & NAs \\
\hline IEDs & 1.321 & 1.803 & -7.699 & 4.675 & 250 & 149 \\
\hline TDT & 0,208 & 0,406 & 0 & 1.000 & 399 & 0 \\
\hline AC & 0,286 & 0,452 & 0 & 1.000 & 399 & 0 \\
\hline PIB & 3.863 & 0,643 & 2.231 & 5.084 & 332 & 67 \\
\hline DIST & 3.884 & 0,227 & 3.165 & 4.275 & 399 & 66 \\
\hline SPIB & 12.289 & 0,24 & 11.946 & 13.245 & 333 & 333 \\
\hline QDIFPIB & 24.270 & 0,65 & 21.043 & 26.202 & & 66 \\
\hline
\end{tabular}

Fonte: elaborada pelos autores (2014)

A Tabela 2 indica os resultados dos modelos estimados por efeitos fixos, efeitos aleatórios e com dados empilhados (pooling).

Tabela 2

Resultados estimados do modelo - IED realizado

\begin{tabular}{cccl}
\hline Variável & Efeitos fixos & Efeitos aleatórios & Pool \\
\hline TDT & $-0,135$ & $0,769^{* *}$ & $0,746^{* *}$ \\
\hline AC & - & 0,344 & 0,287 \\
\hline PIBPC & $-0,515$ & $1,319^{* * *}$ & $1,422^{* * *}$ \\
\hline DIST & - & $-2,581^{* *}$ & $-2,967^{* *}$ \\
\hline SPIB & 0,534 & 0,715 & 0,905 \\
\hline QDIFPIB & 0,494 & 0,136 & 0,114 \\
\hline R quadrado ajustado & 0,04 & 0,269 & 0,349 \\
\hline Observações & 130 & 130 & 130 \\
\hline
\end{tabular}

Legenda: $* \star \star, * \star e *$ denotam significância estatística aos níveis de 1\%,5\% e 10\%, respectivamente.

Fonte: elaborada pelos autores (2014)

Percebe-se que, no modelo de efeitos fixos, não foi possível definir o valor das estimativas dos parâmetros das variáveis AC e DIST, devido a singularidades. Para definir qual modelo melhor se ajusta aos dados, foram realizados o teste F, o teste de multiplicadores de Lagrange de Breusch e Pagan e o teste de Hausman. 
Tabela 3

Testes de especificação do modelo - IED realizado

\begin{tabular}{llcl}
\hline \multicolumn{1}{c}{ Teste } & \multicolumn{1}{c}{ Hipótese testada } & Valor do teste & \multicolumn{1}{c}{ Decisão } \\
\hline Teste F - EF & $\mathrm{H}_{0}=$ Não há efeito (pooling) & $1,708^{* *}$ & Não rejeita $\mathrm{H}_{0^{\prime}}$ pooling \\
\hline LM Breusch e Pagan - EA & $\mathrm{H}_{0}=$ Não há efeito (pooling) & $164,158^{* *}$ & Rejeita $\mathrm{H}_{0^{\prime}}$ efeito aleatório \\
\hline Hausman & $\mathrm{H}_{0}=$ Efeito aleatório & 3,03 & Não rejeita $\mathrm{H}_{0^{\prime}}$ efeito aleatório \\
\hline
\end{tabular}

Legenda: ${ }^{* *},{ }^{* *} \mathrm{e}$ * denotam significância estatística aos níveis de 1\%, 5\% e 10\%, respectivamente.

Fonte: elaborada pelos autores (2014)

Os resultados apresentados na Tabela 3 mostram que o modelo que melhor se adapta aos dados é o modelo de efeitos aleatórios. O primeiro teste denota que não há evidências empíricas para a utilização dos efeitos fixos, sendo a favor do modelo "pooling". Quando testado com o modelo de efeitos aleatórios, há evidências para a utilização deste e, finalmente, quando se testam os modelos de efeitos fixos e aleatórios, novamente há evidências para a utilização do modelo de efeitos aleatórios. Dessa forma, escolheu-se a utilização deste para a análise dos resultados. Cabe aqui destacar que foi realizado o teste de autocorrelação serial, e o resultado de 1,954 mostrou que não há autocorrelação serial nos dados.

É possível observar, através da segunda coluna da Tabela 2, que existe uma relação positiva e significante entre a existência de tratado de dupla tributação e um aumento no volume de investimentos, em se tratando do IED realizado pelo Brasil. O PIB per capita do país receptor do investimento, tendo sido considerado como parâmetro, aponta o nível de renda como o fator de maior impacto na análise de IED realizado dos países nos quais o Brasil investe. A distância para a capital desses países, entretanto, tem um efeito negativo sobre o investimento realizado. Isso se explica pelo fato de as empresas brasileiras serem principiantes no processo de internacionalização e buscarem, inicialmente, mercados mais próximos geograficamente. As outras variáveis não mostraram significância estatística aos níveis usuais de significância.

As estatísticas descritivas das variáveis utilizadas no modelo IED recebido estão apresentadas na Tabela 4, evidenciando que 18,8\% dos países que investiram no Brasil, no período de 2005 a 2011, possuem acordo para evitar a dupla tributação com o país receptor.

Tabela 4

\section{Estatísticas descritivas dos dados - IED recebido}

\begin{tabular}{ccccccc}
\hline Variável & Média & Desvio-Padrão & Mínimo & Máximo & $\mathbf{N}$ & NAs \\
\hline IEDE & 1.407 & 1.851 & -4.398 & 5.242 & 368 & 67 \\
\hline TDT & 0,189 & 0,392 & 0 & 1.000 & 433 & 2 \\
\hline AC & 0,263 & 0,441 & 0 & 1.000 & 433 & 2 \\
\hline PIBPC & 3.939 & 0,188 & 3.676 & 4.100 & 435 & 0 \\
\hline DIST & 3.905 & 0,234 & 3.170 & 4.280 & 435 & 79 \\
\hline SPIB & 12.288 & 0,237 & 11.950 & 13.240 & 356 & 356 \\
\hline QDIFPIB & 24.279 & 0,642 & 20.990 & 26.195 & & 79 \\
\hline
\end{tabular}

Fonte: elaborada pelos autores (2014) 
Tabela 5

Resultados estimados do modelo - IED recebido

\begin{tabular}{|c|c|c|c|}
\hline Variável & Efeitos fixos & Efeitos aleatórios & Pool \\
\hline TDT & $-0,203$ & $1,301 * * \star$ & $1,559 * * *$ \\
\hline$A C$ & - & $-0,697 * *$ & $-0,632 * * *$ \\
\hline PIBPC & $-0,276$ & $-1,896 * \star$ & $-2,275^{\star * *}$ \\
\hline DIST & - & $-1,870 * \star \star$ & $-1,817 * * *$ \\
\hline SPIB & 3,084 & $4,934^{\star \star *}$ & 4,605 *** \\
\hline QDIFPIB & $-0,046$ & $-0,398 * \star \star$ & $-0,515^{* * *}$ \\
\hline R quadrado ajustado & 0,215 & 0,387 & 0,437 \\
\hline Observações & 193 & 193 & 193 \\
\hline
\end{tabular}

Legenda: $* * *, * *$ e * denotam significância estatística aos níveis de 1\%, 5\% e 10\%, respectivamente.

Fonte: elaborada pelos autores (2014)

A Tabela 5 apresentada acima mostra os resultados da estimação dos modelos de efeitos fixos, efeitos aleatórios e pooling para o modelo IED recebido. Assim como no caso anterior, do modelo IED realizado, o modelo escolhido para representar esta relação é o modelo de efeitos aleatórios, conforme os resultados dos testes apresentados na Tabela 6.

Tabela 6

Testes de especificação do modelo - IED recebido

\begin{tabular}{llcl}
\multicolumn{1}{c}{ Teste } & Hipótese testada & Valor do teste & Decisão \\
\hline Teste F - EF & $\mathrm{H}_{0}=$ Não há efeito (Pooling) & $6,244^{* * *}$ & Não rejeita $\mathrm{H}_{0}$, pooling \\
\hline LM Breusch e Pagan - EA & $\mathrm{H}_{0}=$ Não há efeito (Pooling) & $197,297 * \star *$ & Rejeita $\mathrm{H}_{0^{\prime}}$ efeito aleatório \\
\hline Hausman & $\mathrm{H}_{0}=$ Efeito aleatório & 5,606 & Não rejeita $\mathrm{H}_{0}$, efeito aleatório \\
\hline
\end{tabular}

Legenda: $* \star \star, * \star ~ e *$ denotam significância estatística aos níveis de 1\%,5\% e 10\%, respectivamente.

Fonte: elaborada pelos autores (2014)

O modelo de efeitos aleatórios não apresentou autocorrelação serial (o valor do teste foi 2,813 com p-valor 0.093). Neste modelo, a variável TDT é significante e positiva, indicando que os acordos para evitar a dupla tributação aumentam o IED recebido pelo Brasil. A variável SPIB, estatisticamente significante e positiva para esta análise, aponta o tamanho do mercado receptor do investimento, juntamente com o mercado emissor, relevante ao volume de IED recebido pelo Brasil. Essa variável indica que a relação de investimento entre grandes mercados tende a envolver um maior volume de transações e, portanto, países com alto PIB estão propensos a ter grande relação de investimentos entre si.

Os resultados do modelo indicam que os acordos de comércio reduzem o IED recebido. Isso ocorre, possivelmente, pelo fato de o Brasil ter assinado tais acordos majoritariamente com países emergentes - que possuem menor capacidade de investir. O nível de renda da população brasileira não foi positivo para os investidores, justificando o fato de que o maior PIB per capita representa maiores gastos com mão de obra, não impactando os investimentos brasileiros no exterior, pois o país não pode abster-se de investir em mercados importantes e consolidados apenas pelo fato de o nível de renda da população desses países ser superior.

O fato de a variável DIST ter se apresentado com valor negativo justifica-se pelo fato de o influxo de IED no Brasil ser proveniente principalmente de empresas de países desenvolvidos, que já estão em fases avançadas de internacionalização. Dessa forma, a distância geográfica não se torna um grande obstáculo para esses investidores. A variável QDIFPIB tem um efeito negativo sobre o IED recebido pelo Brasil, revelando que, entre 
mercados com maior discrepância de tamanho, há uma tendência de menores fluxos de investimentos. Isso se explica pela dificuldade de existir uniformidade de volume de investimento quando o mercado consumidor de um país está menos propenso a absorver grandes ofertas em comparação ao outro.

De modo geral, os resultados estimados sugerem a significância do papel dos tratados no cenário econômico atual, em que a grande competitividade faz com que a tributação seja um fator preponderante para a decisão de investimento. O resultado encontrado no presente estudo é similar aos resultados encontrados por Barthel, Busse e Neumayer (2010), Neumayer (2007) e Bloningen e Davies (2005), indo de encontro, entretanto, às evidências obtidas nos estudos de Egger et al. (2006) e Bloningen e Davies (2004), que concluíram que os tratados para evitar a dupla tributação não tinham influência positiva no IED.

Destaca-se que esse trabalho possui uma amostra diferente dos anteriores, dado que o presente estudo está restrito ao Brasil (323 observações). O coeficiente de determinação, ainda que inferior a 50\%, segue a tendência dos trabalhos relacionados ao tema, em virtude da dificuldade de selecionar variáveis independentes que consigam explicar de forma robusta a variável dependente "estoque de investimento". Isso se deve à complexidade de tal variável e ao fato de, devido ao tamanho da amostra, haver pouca disponibilidade de dados divulgados que compreendam toda sua extensão, restringindo o montante de variáveis possíveis.

\section{Considerações Finais}

O presente estudo teve como objetivo investigar o impacto dos tratados destinados a evitar a bitributação internacional sobre a renda nas relações de investimento estrangeiro direto do Brasil. Para tanto, foi realizada uma análise de dados em painel com seis variáveis independentes - representam fatores que podem impactar na decisão de investimento, incluindo a presença de tratado para evitar a dupla tributação.

Os resultados obtidos por meio do modelo atestam que há influência positiva e estatisticamente significante dos tratados de dupla tributação nos investimentos que envolvem o Brasil, correspondendo a um aumento no volume de investimento estrangeiro direto. Dividindo-se a amostra entre os investimentos recebidos e realizados pelo Brasil, verificou-se que o aumento foi maior no investimento estrangeiro direto recebido $(130,1 \%)$ do que no realizado $(76,9 \%)$.

As demais variáveis apresentaram, em sua maioria, os resultados esperados, com coeficiente de determinação seguindo a tendência de estudos anteriores de Barthel, Busse e Neumayer (2010) e Neumayer (2007). O número de observações foi condicionado pela quantidade de variáveis e limitado a apenas um país de análise (Brasil).

Conclui-se que, no panorama brasileiro, a bitributação internacional da renda é um ponto relevante na decisão de investimento, pois a presença de tratado que procura assegurar ao investidor que seu rendimento auferido não será duplamente tributado é capaz de incrementar substancialmente os fluxos de investimento.

De forma macro, evidencia-se que o aumento nos investimentos estrangeiros diretos reforça evidências obtidas nos trabalhos de Barthel, Busse e Neumayer (2010), Neumayer (2007) e Bloningen e Davies (2005), ao passo que vão de encontro aos resultados encontrados nos estudos de Egger et al. (2006) e Bloningen e Davies (2004).

Apesar das limitações encontradas no estudo como dados perdidos em todas as variáveis, exceto nas variáveis dummies TDT e AC e na variável DIST e a periodicidade limitada na divulgação dos valores dos investimentos, o presente estudo cumpriu seu objetivo principal de investigar o impacto dos tratados de dupla tributação nos investimentos estrangeiros diretos no cenário brasileiro.

Vale ressaltar que, apesar da técnica empregada neste trabalho, há várias formas de abordagem do tema para estudos futuros, tais como: adoção de métodos estatísticos mais robustos, utilização de outras variáveis determinantes de investimentos, além da possibilidade de que haja uma melhor divulgação dos dados de investimentos e de outras variáveis por parte dos governos dos países, de forma que esteja disponível uma maior quantidade de dados passíveis de análise. 


\section{Referências}

Alvim, A. M., Moraes, S. L. (2013). Os investimentos estrangeiros diretos no Brasil e os impactos sobre o agronegócio - 2002 a 2008. Indicadores Econômicos - FEE. 40, 3, pp. 105-120. Recuperado em 20 agosto, 2014, de http://revistas.fee.tche.br/index.php/indicadores/article/view/2761.

Avi-Yonah, R. S. (2007). International tax as international law: an analysis of the international tax regime. Nova Iorque: Cambridge University Press.

Barthel, F., Busse, M., Krever, R. \& Neumayer, E. (2010). The relationship between double taxation treaties and foreign direct investment. In: M. Lang et al. (Eds.). Tax treaties: building bridges between law and economics. Amsterdã: IBFD. pp. 3-18.

Barthel, F., Busse, M. \& Neumayer, E. (2010). The impact of double taxation treaties on foreign direct investment: evidence from large dyadic panel data. Contemporary Economic Policy, 28(3), pp. 366377. Recuperado em 03 novembro, 2012, de http://personal.lse.ac.uk/barthel/docs/DTT_FDI.pdf.

Bellan, D. V. (2010). Direito tributário internacional: rendimentos de pessoas físicas nos tratados internacionais contra a dupla tributação. São Paulo: Saraiva.

Bloningen, B. A. \& Davies, R. B. (2005). Do bilateral tax treaties promote foreign direct investment? In: Choi, E. K., Hartigan, J. C. (Eds.). Handbook of International Trade, 2, pp. 526-546. Londres: Blackwell.

Bloningen, B. A. \& Davies, R. B. (2004). The effects of bilateral tax treaties on U.S. FDI activity. International Tax and Public Finance, 11(5), pp. 601-622. Recuperado em 04 novembro, 2012, de: http:// darkwing.uoregon.edu/ bruceb/treaty7.PDF.

Collis, J. \& Hussey, R. (2005). Pesquisa em administração: um guia prático para os alunos de graduação e pós-graduação (2a ed.). Porto Alegre: Bookman.

Constituição da República Federativa do Brasil de 1988 (1988). Recuperado em 11 novembro, 2012, de http://www.planalto.gov.br/ccivil_03/constituicao/constituicao.htm. Brasília: Senado.

Convenção de Viena sobre o direito dos tratados, de 23 de maio de 1969 (1969). Viena: Organização das Nações Unidas, 1969. Recuperado em 09 outubro, 2012, de http://dai-mre.serpro.gov.br/clientes/dai/dai/legislacao/convencao-de-viena-sobre-o-direito-dos-tratados-1. Viena: Organização das Nações Unidas.

Corbin, J. \& Strauss, A. (2008). Pesquisa qualitativa: técnicas e procedimentos para o desenvolvimento de teoria fundamentada (2a ed.). Porto Alegre: Artmed.

Croissant, Y. \& Millo, G. (2008). Panel data econometrics in r: the plm package. Journal of Statistical Software, 27(1).

Davies, R. B. (2003). Tax treaties, renegotiations, and foreign direct investment. Economic Analysis and Policy-EAP, 33(2), pp. 251-273. Recuperado em 03 novembro, 2012, de http://economics.uoregon. edu/papers/UO-2003-14_Davies_Tax_treaties.pdf.

Egger, P., Larch, M., Pfaffermayr, M. \& Winner, H. (2006). The impact of endogenous tax treaties on foreign direct investment: theory and evidence. Canadian Journal of Economics, 39(3), pp. 901-931.

Faria, B. C. (2006). A recepção dos tratados internacionais em matéria tributária pelo ordenamento jurídico brasileiro. Dissertação de Mestrado. Universidade Federal do Rio Grande do Sul, Porto Alegre, RS, Brasil. Recuperado em 02 novembro, 2012, de http://www.lume.ufrgs.br/bitstream/handle/10183/7500/000546301.pdf?sequence $=1$

Gonzaga, L. L. B. (2010). A interpretação das convenções contra dupla tributação internacional à luz da teoria da argumentação jurídica. Tese de Doutorado. Universidade de São Paulo, São Paulo, SP, Brasil. Recuperado de http://www.teses.usp.br/teses/disponiveis/2/2133/tde-19112010-084307/pt-br.php

Greene, W. H. (2012). Econometric analysis (7a ed.). Upper Saddle River: Pearson Education. 
Her Majesty's Revenue and Customs (2013). Double taxation treaties. Recuperado em 12 janeiro, 2013, de http://www.hmrc.gov.uk/taxtreaties/dta.htm

Instituto de Pesquisa Econômica Aplicada. (2010). Inserção internacional brasileira: temas de economia internacional (Vol. 2). Brasília: IPEA.

Lei n. 5.172, de 25 de outubro de 1966. Código tributário nacional (1966). Dispõe sobre o sistema tributário nacional e institui normas gerais de direito tributário aplicáveis à União, Estados e Municípios. Recuperado em 22 agosto, 2012, de http://www.receita.fazenda.gov.br/legislacao/CodTributNaci/ ctn.htm. Brasília: Casa Civil.

Lei n. 9.249, de 26 de dezembro de 1995 (1995). Altera a legislação do imposto de renda das pessoas jurídicas, bem como da contribuição social sobre o lucro líquido, e dá outras providências. Recuperado em 26 agosto, 2012, de http://www.receita.fazenda.gov.br/legislacao/leis/ant2001/lei924995.htm. Brasília: Senado.

Mazzuoli, V. O. (2011). Curso de direito internacional público (5ª ed.). São Paulo: Revista dos Tribunais.

Moreira, A. M. (2003). Dupla imposição internacional - métodos unilaterais e multilaterais contra os excessos tributários. Revista Eletrônica da Associação Brasileira de Direito Tributário, 25, pp. 2-8. Recuperado em 27 julho, 2012, de http://sachacalmon.com.br/wp-content/uploads/2010/10/Dupla-Imposicao-Internacional-metodos-unilaterais-e-multilaterais-contra-os-excessos-tributarios.pdf.

Neumayer, E. (2007) Do double taxation treaties increase foreign direct investment to developing countries? Journal of Development Studies, 43(8), pp. 1501-1519. Recuperado em 08 novembro, 2012, de http://eprints.lse.ac.uk/3054/

Organização para Cooperação e Desenvolvimento Econômico (2010). Artigos da convenção modelo da OCDE sobre a tributação da renda e do capital. Recuperado em 15 dezembro, 2012, de: http://www. oecd.org/tax/taxtreaties/47213736.pdf.

Paixão, M. C. S. (2014). Investimento estrangeiro direto industrial no cenário ambiental e socioeconômico do Nordeste brasileiro. Tese de Doutorado. Universidade de Brasília, Brasília, DF, Brasil. Recuperado em 29 setembro, 2014, de http://repositorio.unb.br/handle/10482/16301.

R Foundation for Statistical Computing (2014). A language and environment for statistical computing. Recuperado em 23 setembro, 2014, de http://www.r-project.org/

Receita Federal do Brasil (2012). Acordos para evitar a dupla tributação. Recuperado em 25 julho, 2012, de http://www.receita.fazenda.gov.br/Legislacao/AcordosInternacionais/Acordos DuplaTrib.hth

Receita Federal do Brasil (2014). O Investimento Direto Estrangeiro - IDE. Recuperado em 25 outubro, 2014, de http://www.receita.fazenda.gov.br/aduana/IDE/IDEBrasilCuba/ide.htm

Roesch, S. A. (2006). Projetos de estágio e pesquisa em administração: guia para estágios, trabalhos de conclusão, dissertações e estudos de caso ( $3^{\mathrm{a}}$ ed.). São Paulo: Atlas.

Silva, G. B. (2008). Dupla tributação internacional. Monografia de Especialização. Instituto Brasiliense de Direito Público, Brasília, DF, Brasil. Recuperado de http://dspace.idp.edu.br:8080/xmlui/bitstream/ handle/123456789/354/Monografia_Getulio\%20Borges\%20da\%20Silva.pdf?sequence=1

Silva, L. M. (2007). Tratados internacionais sobre dupla tributação da renda e suas consequências na tributação dos rendimentos obtidos no exterior por pessoas jurídicas com domicílio no Brasil [versão eletrônica], Revista do Mestrado em Direito - UCB, 1(2), pp. 21-61.

Wooldridge, J. M. (2010). Econometric analysis of cross section and panel data (2 $2^{\mathrm{a}} \mathrm{ed}$.). Cambridge: MIT Press.

Wu, W. J. (2008). Bilateral tax treaties and Taiwan's FDI activity. Anais do International Symposium: Recent Development in Taiwan's Taxation, Tóquio, Japão, 1.

Xavier, A. (2007). Direito tributário internacional do Brasil (6a ed.). Rio de Janeiro: Forense. 